Article

\title{
Detection of Lipid Oxidation in Infant Formulas: Application of Infrared Spectroscopy to Complex Food Systems
}

\author{
Samar Daoud ${ }^{1, * \mathbb{D}}$, Elias Bou-Maroun ${ }^{1} \mathbb{D}$, Gustav Waschatko ${ }^{2}$, Benjamin Horemans ${ }^{2}{ }^{\mathbb{D}}$, \\ Renaud Mestdagh $^{2}$, Nils Billecke ${ }^{2}\left(\right.$ i) and Philippe Cayot ${ }^{1}$ (D) \\ 1 Unité Mixte "Procédés Alimentaires et Microbiologiques", Université Bourgogne Franche-Comté, \\ AgroSup Dijon, PAM UMR A 02.102, F-21000 Dijon, France; elias.bou-maroun@agrosupdijon.fr (E.B.-M.); \\ philippe.cayot@agrosupdijon.fr (P.C.) \\ 2 Cargill R\&D Centre Europe BVBA Havenstraat 84, B-1800 Vilvoorde, Belgium; \\ gustav_waschatko@cargill.com (G.W.); benjamin_horemans@cargill.com (B.H.); \\ renaud_mestdagh@cargill.com (R.M.); nils_billecke@cargill.com (N.B.) \\ * Correspondence: samar.daoud@u-bourgogne.fr
}

Received: 30 August 2020; Accepted: 30 September 2020; Published: 9 October 2020

\begin{abstract}
Fish- or algal oils have become a common component of infant formula products for their high docosahexaenoic acid (DHA) content. DHA is widely recognized to contribute to the normal development of the infant, and the European Commission recently regulated the DHA content in infant formulas. For many manufacturers of first-age early life nutrition products, a higher inclusion level of DHA poses various challenges. Long-chain polyunsaturated fatty acids (LC-PUFAs) such as DHA are very prone to oxidation, which can alter the organoleptic property and nutritional value of the final product. Traditional methods for the assessment of oxidation in complex systems require solvent extraction of the included fat, which can involve harmful reagents and may alter the oxidation status of the system. A rapid, efficient, non-toxic real-time method to monitor lipid oxidation in complex systems such as infant formula emulsions would be desirable. In this study, infrared spectroscopy was therefore chosen to monitor iron-induced oxidation in liquid infant formula, with conjugated dienes and headspace volatiles measured with GC-MS as reference methods. Infrared spectra of infant formula were recorded directly in mid- and near-infrared regions using attenuated total reflectance Fourier-transform (ATR-FTIR) and near-infrared (NIRS) spectrophotometers. Overall, good correlation coefficients $\left(R^{2}>0.9\right)$ were acquired between volatiles content and infrared spectroscopy. Despite the complex composition of infant formula containing proteins and sugars, infrared spectroscopy was still able to detect spectral changes unique to lipid oxidation. By comparison, near-infrared spectroscopy (NIRS) presented better results than ATR-FTIR: prediction error ATR-FTIR 18\% > prediction error NIRS 9\%. Consequently, NIRS demonstrates great potential to be adopted as an in-line or on-line, non-destructive, and sustainable method for dairy and especially infant formula manufacturers.
\end{abstract}

Keywords: infant formula; lipid oxidation; infrared spectroscopy; NIR; ATR-FTIR; DHA

\section{Introduction}

Omega-3 long-chain polyunsaturated fatty acids (LC-PUFAs) such as alpha-linolenic acid (ALA, C18:3), eicosapentaenoic acid (EPA, C20:5), and docosahexaenoic acid (DHA, C22:6) are well known to improve brain and nervous system development in infants and young children [1-4]. The European Food Safety Authority (EFSA), among other authoritative bodies, recommends a higher intake of omega-3 fatty acids, especially at a young age [3]. In the European Union, the addition of 
DHA to infant formula and follow-on formula became compulsory [5]. Infant milk formulas represent the only food for newborns, performing a crucial nutritional role [6]. Formulas enriched in DHA are extremely prone to oxidation, which poses the risk of exposing the infant to harmful degradation products. Not only do the included LC-PUFAs have a high degree of unsaturation [7], but the addition of prooxidants such as iron to meet nutritional requirements [5] also poses a challenge to the stability of the final product. Hydroperoxides are the first oxidation products and are very reactive, breaking down rapidly to aldehydes, ketones, and other volatiles. These secondary products of lipid oxidation are responsible for rancidity and off-flavors [8]. Oxidized flavors are noticeable in stored milk at low levels of oxidation (peroxide value $<1$ meq. $\mathrm{O}_{2} / \mathrm{kg}$ oil). "Fishy" and "metallic" attributes were correlated with increased concentrations of hexanal and heptanal and have been shown to be particularly evident in infant milk formula enriched with LC-PUFA [8-10]. Moreover, multiple lipid oxidation products (such as free radicals, reactive oxygen species, and aldehydes) may exert detrimental effects on vital biological processes, potentially leading to tissue injuries and increasing the risk for degenerative diseases [11-13].

To ensure the safety and quality of the supplemented food, an efficient method to measure lipid oxidation is required. So far, the determination of hydroperoxides (peroxide value (PV) or conjugated diene (CD) value) and aldehydes (thiobarbituric acid reactive species (TBARS)) in infant formula were conventionally used $[9,14,15]$. However, determining the oxidative status of oil in food matrices such as infant formula requires the extraction of fats and oils. This step is time consuming, involves harmful solvents, and may induce under- or overestimation of oxidation levels $[15,16]$. In addition, in-line implementation in industrial production lines is not possible. Liquid or gas chromatography was also used traditionally to monitor lipid oxidation in infant formulas $[10,17,18]$. However, chromatography analysis requires long sample preparation and the addition of reagents and standards for quantification. A rapid, accurate, and direct method may reduce effort, analysis time, and, subsequently, costs.

Spectral and multivariate analyses enable the use of infrared spectroscopy as a practical tool for food examination [19]. In the mid infrared region (4000-600 $\left.\mathrm{cm}^{-1}\right)$, spectral signatures result from the fundamental stretching, bending, and rotating vibrations of the tested sample molecules. Absorptions in near-infrared (NIR) regions 800 to $2500 \mathrm{~nm}\left(12,500-4000 \mathrm{~cm}^{-1}\right)$ correspond to overtones and combinations of the fundamental bands [20]. Infrared spectroscopy has been increasingly applied for several food matrices to measure adulteration in olive oil [21,22], water content [23], fat, and protein content in cereal food [24]. However, infrared spectroscopy is also very useful to measure lipid oxidation. Good correlations were observed between spectral data and the formation of oxidation products. Several studies presented near infrared spectroscopy (NIRS) correlations with oxidation products of bulk oils [25-27]. Spectra in the mid-infrared region using FTIR also showed good prediction of oxidation levels in bulk oil [28-31].

However, studies using infrared spectroscopy (NIRS and FTIR) to monitor lipid oxidation in complex food systems are still scarce, and only a few studies analyzed oil oxidation in emulsions [32-37]). These emulsion-oxidation studies depend on a fat extraction step prior to analysis. NIRS applications in the oxidation monitoring of complex "foods" and not bulk oils were limited: whole walnut kernels [38], cereal food products [39], and potato crisps [40]. Infrared spectroscopy was also shown once to monitor oxidation in infant formula powder [41]. However, in these applications, infrared spectroscopy was applied after fat extraction and on products with low water contents.

Infrared spectroscopy offers several advantages over conventional methods, including high speed, minimal sample volume and preparation, and no chemical wastes. In addition, compared to other spectroscopic tools (e.g., attenuated total reflectance Fourier-transform infrared ATR-FTIR, or Raman) NIRS sensors can be used in-line or on-line for the liquid process streams. Regarding all these criteria, infrared spectroscopy is considered, as a "green analytical tool" [20,42,43]. Its use for lipid oxidation evaluation could be a practical approach for food industries where quick, reliable, and accurate assessment of the quality of products are needed. 
This study aims to evaluate the ability of infrared spectroscopy in near-(NIRS) and mid-(ATR-FTIR) infrared regions to predict iron-initiated lipid oxidation in infant milk formulas without prior fat extraction. Milk formulas were prepared and kept at different storage conditions. Iron was used as an oxidation initiator, and a blend of antioxidants was included in the formula. Oxidation levels were monitored as well by standard technics such as conjugated diene values (CD), and total volatile content measured by solid-phase microextraction (SPME) gas-chromatography coupled to mass spectrometry (GC-MS). Correlations of these standard values with spectral changes were performed using partial least squares regression (PLSR).

\section{Materials and Methods}

Skimmed milk powder LF100, whey protein (Lactarmor ${ }^{\mathrm{TM}}$ DM 90), lactose, and glucose were obtained from Armor Proteins, Rennes, France. The fat blend was a mixture of fish and vegetables oils $(45 \%(v / v)$ palm, $20 \%(v / v)$ coconut, $25 \%(v / v)$ rapeseed, and $10 \%(v / v)$ sunflower oils) commonly used in the making of an infant formula. This mixture was delivered by Cargill R\&D center (Vilvoorde, Belgium). The mixture contained $1.3 \% w / w$ of DHA in the final product. This percentage corresponds to the recent regulations of DHA addition in infant formula [5]. The antioxidants were ascorbyl palmitate (CAS Number 137-66-6), citric acid monohydrate (CAS Number 5949-29-1), and soybean lecithin, which was supplied by Cargill R\&D Europe Center (Vilvoorde, Belgium).

Ferrous sulfate heptahydrate (CAS Number 7782-63-0) was added to initiate lipid oxidation. Fat extraction and conjugated diene measurements were performed using isooctane (CAS Number 540-84-1), 2-propanol (CAS Number 67-63-0), and sodium chloride (CAS Number 7647-14-5). All reagents and solvents were analytical grade and purchased from Merck Sigma Aldrich (Munich, Germany).

\subsection{Infant Milk Formula Production and Oxidation Conditions}

Infant milk formulas consisted of $50 \%(w / w)$ of a powder mixture and $50 \%(w / w)$ of water containing ferrous sulfate added at $195 \mathrm{ppm}$ (final concentration in formulas $3.5 \mathrm{mM}$ of $\mathrm{Fe}^{2+}$ ). First, standardized tap water $(300 \mathrm{~g})$ was preheated at $60^{\circ} \mathrm{C}$ with stirring at $800-1000 \mathrm{rpm}$. Second, skimmed milk powder $(40.8 \mathrm{~g})$ and whey protein $(112.5 \mathrm{~g})$ were added. After $5 \mathrm{~min}$ of continuous stirring, lactose $(47.7 \mathrm{~g})$ and glucose $(14.1 \mathrm{~g})$ were poured in and stirred for $30 \mathrm{~min}(500 \mathrm{rpm})$ at $60^{\circ} \mathrm{C}$. Oil mixture $(84.9 \mathrm{mg})$ containing fish oil was added to the aqueous phase to obtain a final volume fraction of $14 \%(v / v)$. A pre-emulsification step was completed using a homogenizer (Ultra Turrax ${ }^{\circledR} \mathrm{T} 25$, IKA ${ }^{\circledR}$ Labortechnik, Staufen, Germany) for $30 \mathrm{~s}$ at $12,000 \mathrm{rpm}$. Samples were then homogenized at $60{ }^{\circ} \mathrm{C}$ with a two-stage valve-type homogenizer (220/30 bar) for three passages (Panda plus, GEA, Niro Soavi, Parma, Italy). The $\mathrm{pH}$ was adjusted to $6.5-6.7$ with a $1 \mathrm{M}$ potassium hydroxide $(\mathrm{KOH})$ solution. Samples were heated for $1 \mathrm{~min}$ at $85^{\circ} \mathrm{C}$ and stirred at $400 \mathrm{rpm}$ to mimic the pasteurization step. Using this protocol, two types of infant milk formulas were produced. The first recipe contained no antioxidants (No-AOx). For the second recipe, a mixture of antioxidants containing ascorbyl palmitate (250 ppm) and citric acid (235 ppm) was included. In addition, soybean lecithin (1900 ppm) was added as an emulsifier and potential antioxidant (AOx).

Four grams of each sample were transferred into $20 \mathrm{~mL}$ brown capped vials. These samples were flushed with oxygen for $30 \mathrm{~s}$ and kept at 50,60 , and $70^{\circ} \mathrm{C}$. These conditions were set to significantly increase the oxidation rate. At lower temperatures $\left(<40^{\circ} \mathrm{C}\right)$ and in sealed containers, infant milk formula can remain stable for at least 3 months $[9,18]$. For each set of samples, three replicates were prepared. Through storage, samples were analyzed with infrared spectroscopy and reference methods.

\subsection{Conjugated Diene Determination (CD Values)}

The determination of $C D$ values was selected in this study as a reference method. First, the fat phase was extracted as described in our previous work [32]. Briefly, samples $(0.2 \mathrm{~g})$ isooctane/2-propanol 
$(3 / 1, v / v)$ solution $(1 \mathrm{~mL})$ and sodium chloride $(0.024 \mathrm{~g})$ were placed in plastic tubes. The mixture was strongly shaken using a vortex device for $1 \mathrm{~min}$ and left to stand for $1 \mathrm{~min}$ for phase separation.

Afterward, the American oil chemist society (AOCS) official method Ti 1a-64 [44] was applied with slight modifications. The upper layer $(20-50 \mu \mathrm{L})$ was diluted in isooctane. The UV-Vis spectra were recorded in the range of 200 to $300 \mathrm{~nm}$ using a UV-Vis spectrophotometer (SAFAS, Monaco). The data interval and the band path were set at 1 and $2 \mathrm{~nm}$, respectively. The conjugated dienes have a maximum absorbance near $233 \mathrm{~nm}$. Pure isooctane was used as a reference to set the spectrometer to zero absorbance.

\subsection{Total Volatile Measurements using GC-MS}

Volatiles were extracted by headspace solid-phase microextraction (HS-SPME) using MPS autosampler (Gerstel, Baltimore, MD, USA). Prior to fiber insertion, $4 \mathrm{~g}$ of infant formula in a $20 \mathrm{~mL}$ vial was placed at $70{ }^{\circ} \mathrm{C}$ for $2 \mathrm{~min}$ at an agitation rate of $500 \mathrm{rpm}$. A $(1 \mathrm{~cm} 100 \mu \mathrm{m})$ polydimethylsiloxane (PDMS) fiber (Supelco, Bellefonte, PA, USA) was then introduced into the HS and the vial was agitated at $250 \mathrm{rpm}$ for $5 \mathrm{~min}$ at $70^{\circ} \mathrm{C}$.

Afterward, volatiles were thermally desorbed into the injector of an Agilent 7890 gas chromatograph coupled to a time-of-flight accurate mass spectrometer (GC/Q-TOF-MS, Agilent technologies, Santa Clara, CA, USA). The injections were splitless for $1 \mathrm{~min}$ at $300^{\circ} \mathrm{C}$. A HP-5MS column $(30 \mathrm{~m} \times 250 \mu \mathrm{m}$ i.d. $\times 0.25 \mu \mathrm{m}$ film thickness) from Agilent Technologies Inc. (Santa Clara, CA, USA) was used. The column temperature was programmed as follows: initial hold for $2 \mathrm{~min}$ at $40{ }^{\circ} \mathrm{C}$, followed by a $15{ }^{\circ} \mathrm{C} / \mathrm{min}$ ramp to $185^{\circ} \mathrm{C}$ and then, $120^{\circ} \mathrm{C} / \mathrm{min}$ ramp to $300{ }^{\circ} \mathrm{C}, 1 \mathrm{~min}$ hold. The carrier gas was helium (flow rate of $1.5 \mathrm{~mL} / \mathrm{min}$ ). The detector temperature was placed at $300^{\circ} \mathrm{C}$. The TOF-MS was operated in electron impact mode (ionization energy of $70 \mathrm{eV}$ ). All samples were analyzed, at least, in triplicates to measure the volatiles derived from lipid oxidation. Results were expressed as area responses (counts).

\subsection{Near-and Mid-Infrared Measurements}

The infrared spectrometer Nicolet iS50-FT-IR, from Thermo Scientific (Waltham, MA, USA), was used to record infrared spectra. The spectrometer was coupled to an ATR accessory (ZnSe crystal, Smart iTX, Thermo Scientific, USA). Samples were spread directly on the crystal surface, and the absorbance spectrum was collected. A dry and empty ATR cell was used as a reference. The ATR spectra were averaged over 16 scans from 4000 to $600 \mathrm{~cm}^{-1}$ and recorded with a resolution of $4 \mathrm{~cm}^{-1}$. All measurements were conducted at room temperature. The crystal was cleaned with ethanol and water.

For the near-infrared region (NIR), a near-IR integrating sphere (Thermos Scientific, Waltham, MA, USA) accessory was coupled to the spectrometer. Likewise, spectra were measured directly with no sample preparation. The spectrum was recorded in the range of $10,000-4000 \mathrm{~cm}^{-1}$, with 16 scans and $8 \mathrm{~cm}^{-1}$ resolution. Finally, measurements were made in triplicates.

\subsection{Pretreatment and Multivariate Data Analysis}

Data analysis was performed using the TQ Analyst software (version 9; Thermo Scientific, Waltham, MA, USA). PLSR was used to establish correlations between the infrared spectra features and the oxidation level obtained by the standard reference methods (conjugated diene and volatile contents by GC-MS).

Background noises were observed in the spectral data. Thus, preprocessing the spectral data was essential to produce accurate and stable calibration models [19]. Various methods were investigated. In the near-infrared region, the second derivative (gap 23 points, segment 19 points) was chosen to remove baseline shifts and increase the spectral resolution [45]. PLSR models were designed using the spectral range of $800-2400 \mathrm{~nm}$ for $\log 1 / \mathrm{T}$ data. Conversely, the range from $4000-600 \mathrm{~cm}^{-1}$ was selected 
for the mid-infrared region. In this region, the standard normal variate (SNV) followed by baseline correction was used to reduce interference and baseline shifts and to increase spectral resolution.

Afterward, samples were divided randomly into two sets for calibration and validation purposes, using the random feature provided in the TQ Analyst software. Since the validation of this model was ensured by an external set of samples (validation set), the root mean square error of validation (RMSEV) can be defined as the RMSE of prediction (RMSEP). The number of PLSR factors was selected to ensure a minimum root mean square error of prediction (RMSEP) [46]. The coefficient of determination $\left(R^{2}\right)$, the root mean square error of calibration (RMSEC), and prediction (RMSEP) were selected to evaluate the performance of each model. When the coefficient of determination $\left(R^{2}\right)$ was closer to 1 , and the RMSEC and RMSEP were the lowest, a model was judged efficient [47-49]. Furthermore, the ratio of the standard error of performance (SEP) to the standard error of calibration (SEC) must be less than 1.2. However, to identify the usage of the developed model, the ratio of the data range $(R)$ to the SEP should be evaluated. When it is superior or equal to 4 , the model can only be used for screening calibration. When this ratio is superior or equal to 10 , the model is suitable for quality control. Once this ratio is superior or equal to 15, the model can be applied for quantification studies [50]. The residual prediction deviation (RPD) value can be also checked for model performance. The RPD is calculated as the ratio of (standard error of) performance to (standard) deviation (RPD) $=\mathrm{SD}$ of data/SEP. SD/SEP $\geq 2.5$ means screening in breeding programs; SD/SEP $\geq 5$ means acceptable for quality control; and SD/SEP $\geq 8$ means good for process control, development, and applied research [50].

To assess significant differences, the analysis of variance (one-way ANOVA), followed by means comparison using the Tukey test, was used. The level of significance was set to $95 \%(p=0.05)$. Statistical tests were performed using the Minitab ${ }^{\circledR}$ (version 18.1; State College, PA, USA).

\section{Results and Discussion}

\subsection{Oxidation Monitoring by Reference Methods}

\subsubsection{Determination of Conjugated Diene Values}

The oxidation level was evaluated using the conjugated dienes method. Figure 1 shows the variation of absorbance at $233 \mathrm{~nm}$ for infant milk formulas (with iron and without antioxidants addition) stored in the dark at $70{ }^{\circ} \mathrm{C}$ for 7 days. The value of the absorbance at $233 \mathrm{~nm}$ was extremely low and below the linearity range (0.2-0.8) of the UV spectrometer. However, signs of lipid oxidation (off-flavors, color changing) for both conditions were detected.

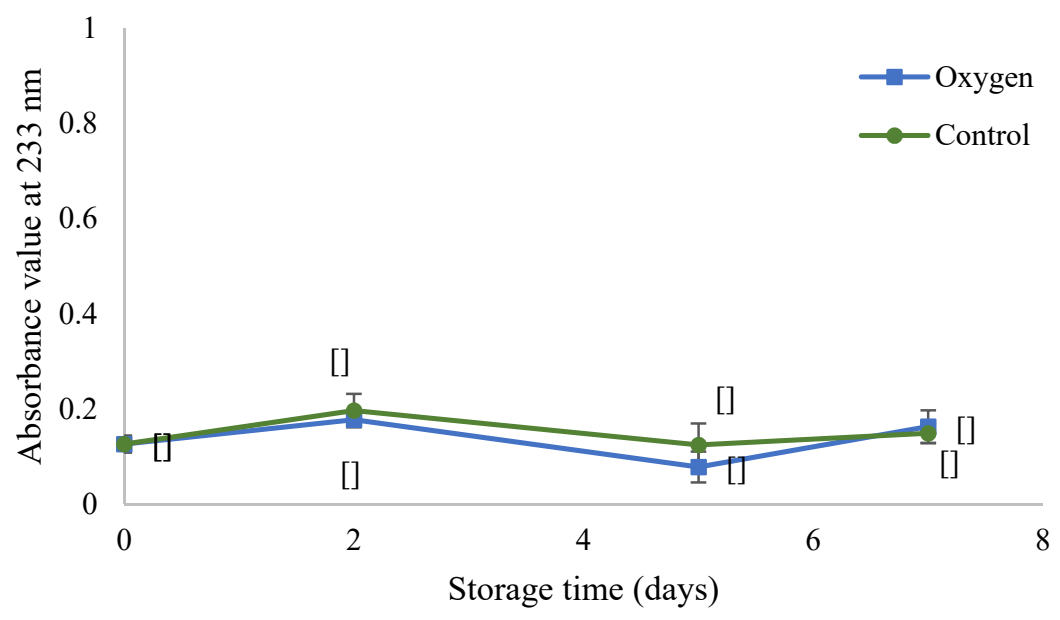

Figure 1. Variation in absorbance at $233 \mathrm{~nm}$ (conjugated diene (CD) values) of liquid infant milk formula stored under pure oxygen in the head space ( $\bullet$ oxygen) or under air $(\bullet)$. 
Iron $\left(\mathrm{Fe}^{2+}\right)$ was added at $3.510^{3} \mu \mathrm{M}$. Formulas were flushed with oxygen $(\mathbf{\square})$ or not $(\bullet)$ (control sample under normal air atmosphere). Samples were kept in the dark for 7 days at $70{ }^{\circ} \mathrm{C}$. Data are shown as means of two replicates and three repetitions each one $\pm \mathrm{SD}(n=6)$. Common letters indicate no significant difference within the same conditions according to ANOVA $(p<0.05)$.

The $\mathrm{CD}$ value was around $1 \mathrm{mmol}$ of eq. peroxide/ $\mathrm{kg}$ emulsion for both conditions (oxygen or ambient air), without any differences. Determination of $C D$ was unsuitable for detecting the lipid oxidation in infant milk formula in this study. When monitoring conjugated dienes, relatively long storage intervals i.e., 3 to 6 months, were necessary to notice changes in the stability of infant formulas [10]. In our previous work on the oil-in-water emulsion, the CD method allowed the monitoring of lipid oxidation [32], which was due to the higher content of sensitive oils in the samples there, emulsion contained $20 \%(v / v)$ pure tuna oil. In contrast, infant milk formula contains $14 \%(v / v)$ of fat which represents a mixture of fish (approx.1.3\% $(v / v)$ of total fat) and vegetable oils. The formation of conjugated dienes is closely related to the number of unsaturation of fatty acids [11]. Therefore, in infant milk, the content of conjugated dienes is not representative of the oxidation level. Subsequently, oxidation was assessed using GC-MS as a reference method.

\subsubsection{Measurement of Released Volatiles by HS-SPME/GC-MS}

HS-SPME/GC-MS was used to monitor changes in the key volatile compounds in infant milk formula. The lipid profile of infant formula differs regarding the intended uses (first age, follow-on formulas, etc.). Nevertheless, the main fat part of all infant formulas consists of a mixture of vegetable oils (coconut, palm, corn, sunflower, rapeseed, etc.). Palmitic (C16:0), oleic (C18:1), linoleic (C18:2), and linolenic (C18:3) acids are the major fatty acids [51]. Once oxidized, these fatty acids will be transformed into hydroperoxides $(\mathrm{LOOH})$. The decomposition of $\mathrm{LOOH}$ by scission reaction leads to lower-molecular-weight compounds such as aldehydes, ketones, alkanes, and alcohols (secondary products of oxidation). These volatiles are responsible for off-flavors and rancidity [11].

Ten aldehydes were chosen to represent oxidation products of oleic, linoleic, and linolenic acids. Octanal, nonanal, decanal, and 2-decenal were used to track oleic acid oxidation. Hexanal, 1-octene-3-ol, 2-nonenal, and 2,4-decadienal were used as key volatiles of linoleic acid oxidation. As for linolenic acid, 2-pentenal/2-hexenal was measured as the main volatile of its oxidation. These are the main aldehydes produced for each fatty acid [10,52]. Hexanal was the major aldehyde with the highest response area value (Supplementary Materials Figure S1). The other compounds slightly increased. However, 2,4-decadienal showed a small decrease (Supplementary Materials Figure S2). This can be explained by the transformation of 2,4-decadienal in 2-octenal and hexanal by retro-aldolization. This mechanism was described in a study on poultry meat [53]. Therefore, the sum of all the response areas for the ten aldehydes was used to interpret the results.

Samples were flushed with oxygen and stored at 50,60 , and $70^{\circ} \mathrm{C}$. As expected, high temperatures resulted in faster oxidation. At $70^{\circ} \mathrm{C}$, the sum of these aldehydes (area responses) went approximately two times higher than that at $60^{\circ} \mathrm{C}$ (Figure 2). As at $50^{\circ} \mathrm{C}$, no significant changes were seen. These values were in the range of $\mu \mathrm{mol} / \mathrm{kg}$ sample. High storage temperature increased the production of volatiles in infant milk formula. Similar results were observed in a study on infant milk formula in powder form [18]. Temperature not only increases the rate of hydroperoxide decomposition but also induces changes in the repartition (percentage, cis/trans ratio) of the resulting degradation products [11].

Two preparations of infant milk formulas were studied. The first recipe (No-AOx) did not contain antioxidants. As for the second one (AOx), a mixture of ascorbyl palmitate (E304), citric acid (E330), and lecithin (E322) as a surfactant was used. Figure 3 shows a comparison between these two formulations after storage at $70^{\circ} \mathrm{C}$ for 8 days. Even at $70{ }^{\circ} \mathrm{C}$, the antioxidants mixture had a preventive effect. The total sum of volatiles remained stable after 8 days. 


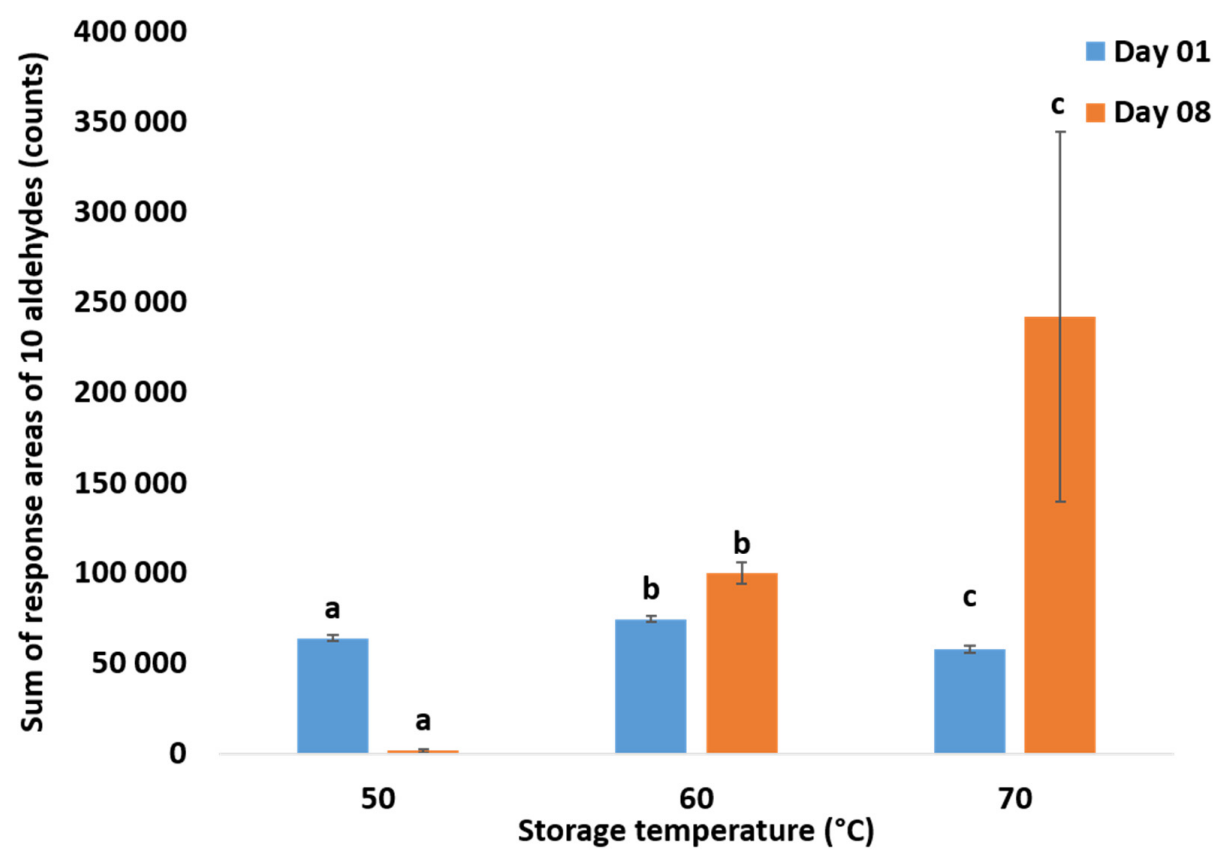

Figure 2. Impact of storage temperature on the sum of volatiles (response areas) determined by solid-phase microextraction (SPME)-GC-MS in a liquid infant milk formula. Samples were stored in the dark for 8 days at 50,60 , and $70{ }^{\circ} \mathrm{C}$ and contained no antioxidants. Values are presented as means. Error bars are standard deviations of three repetitions. Means with different letters within the same day are significantly different (one-way ANOVA $p<0.05$; factor: storage temperature $\left({ }^{\circ} \mathrm{C}\right)$ ).

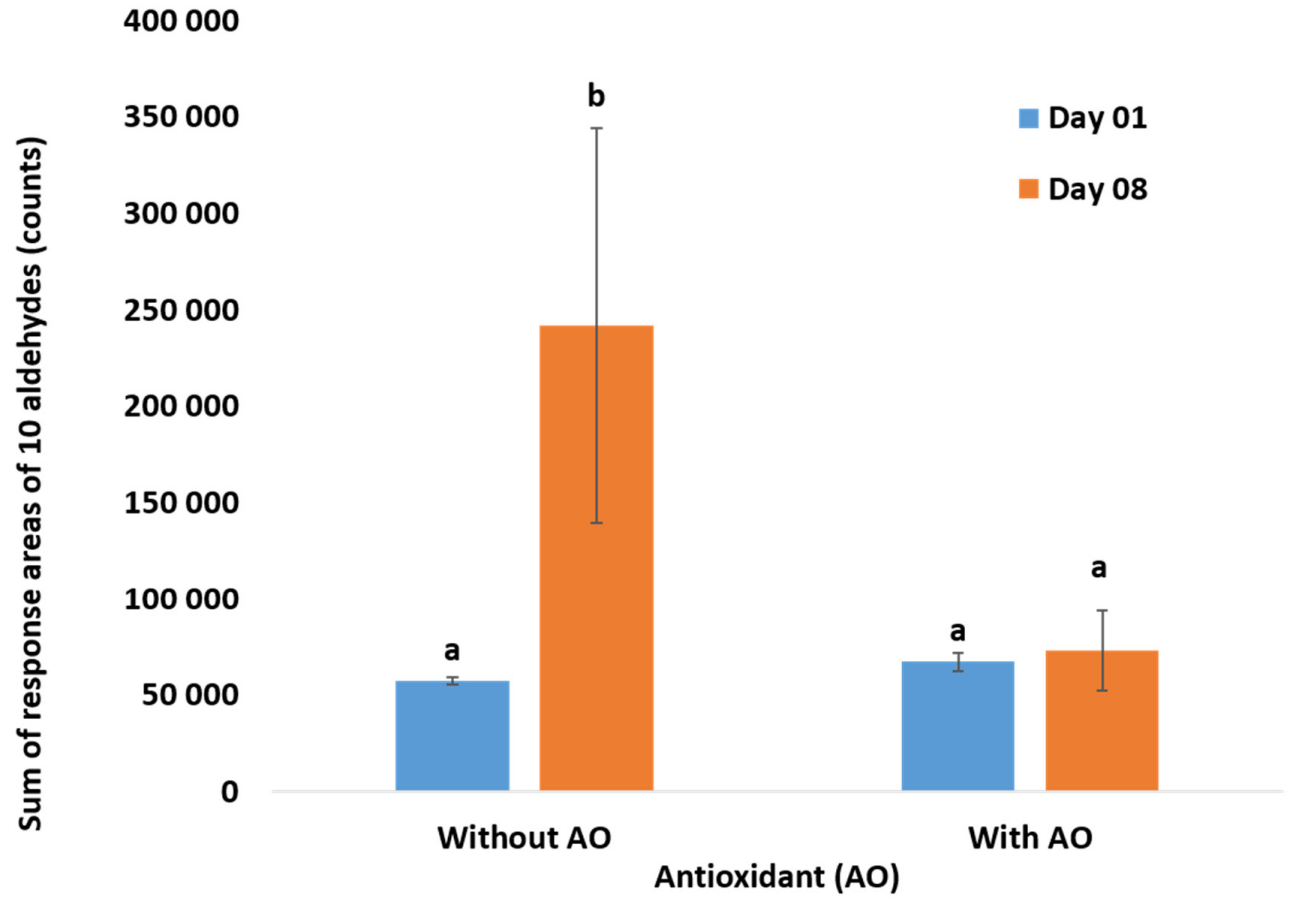

Figure 3. Impact of citric acid, lecithin, and ascorbyl palmitate on the sum of volatiles (responses area) determined by SPME-GC-MS in a liquid infant milk formula. AO means antioxidants and corresponds to the mixture of citric acid, ascorbyl palmitate (E304), and lecithin (use to present an antioxidant activity). The emulsion is stabilized by milk protein. Infant milk formula with antioxidants and without antioxidant (no additives) was stored for 8 days at $70{ }^{\circ} \mathrm{C}$. Values are means and errors bars are standard deviation of three repetitions. Means with different letters are significantly different (one-way ANOVA $p<0.05$; factor: storage time (days)). 
The selected antioxidant mixture proved its efficiency even at elevated temperatures. Though lecithin is not classified as a metal ions chelator, or a radical scavenger, it is known for its antioxidant activity. Lecithin's antioxidant activity can be related to its synergy with other antioxidants (e.g., tocopherols) [54-56]. Citric acid chelates iron and retards lipid oxidation [57]. Ascorbyl palmitate has the ability to react with oxygen, scavenge radicals (excited dioxygen, $\mathrm{O}_{2}$ e.g., or two $\mathrm{ROO}$ ), and act in synergy with other antioxidants, for example, by regenerating tocopherol radicals in tocopherols $[11,58]$. In addition, the added mixture not only combined different antioxidant strategies but also had different sites of action: citric acid in the aqueous phase, ascorbyl palmitate in the oil phase, and lecithin at the interface and in the aqueous phase (in micelle state when its concentration is over the critical micelle concentration (CMC)). In conclusion, when the antioxidant mixture was added, slight changes were occurring in the volatiles' content even at high temperature. These results confirmed that the variations identified during storage are mainly related to lipid oxidation and not to protein's reaction with reducing sugars (Maillard reactions) or sugar crystallization.

\subsection{Infrared Spectroscopy in Mid-Region ATR-FTIR Applied to Infant Milk Formulas}

\subsubsection{Spectral Changes in Infant Milk Formulas}

The FTIR spectra of infant milk formulas were recorded in the range of $4000-400 \mathrm{~cm}^{-1}$. The same absorbance bands were observed for both formulations under different storage conditions. However, changes were noticed after one and six days of storage for samples without and with antioxidants, respectively (Supplementary Materials Figure S3). Attenuation of the bands was more pronounced at higher temperature $\left(70^{\circ} \mathrm{C}\right)$. Figure 4 shows an overlay of the ATR-FTIR spectra of the No-AOx infant formula stored in dark at $70^{\circ} \mathrm{C}$. Several constituents (proteins, carbohydrates, and fats) of infant formula were absorbing in mid-infrared region.

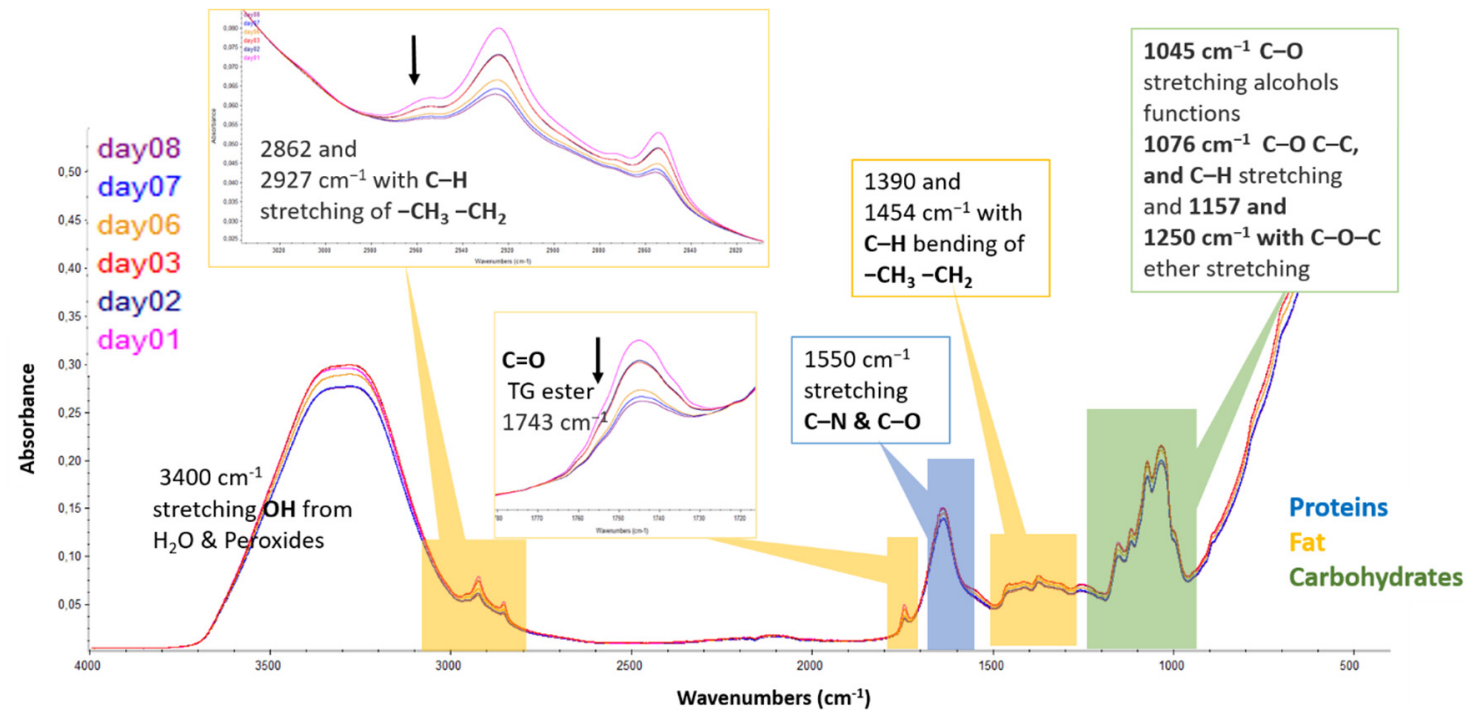

Figure 4. Variation of attenuated total reflectance Fourier-transform infrared (ATR-FTIR) spectra (4000-400 $\mathrm{cm}^{-1}$ ) of liquid infant milk formula without antioxidants stored in dark at $70{ }^{\circ} \mathrm{C}$ for 8 days.

Spectra are the average of three repetitions on three different subsamples. Standard normal variate (SNV) and baseline correction were applied on spectral data.

The first region (3800-2700 $\mathrm{cm}^{-1}$ ) contains the broad water band near $3400 \mathrm{~cm}^{-1}$. This band represents the stretching vibrations of the hydroxyl group $(\mathrm{OH})$ from water and hydroperoxides. During storage, the bands at 3012, 2862, and $2927 \mathrm{~cm}^{-1}$ decrease, these band are related to fat $[59,60]$. They represent the stretching vibration of $\mathrm{C}-\mathrm{H}$ of the cis double bond $(\mathrm{C}=\mathrm{C}), \mathrm{CH}_{3}$, and $\mathrm{CH}_{2}$, respectively. 
Once lipids are oxidized, the cis-double bond rearranges to form a trans-double bond, resulting in the decrease of the band at $3012 \mathrm{~cm}^{-1}[28,36,61]$.

The next infrared region $\left(1800-1500 \mathrm{~cm}^{-1}\right)$ reveals bands from both protein and fat $[59,60]$. It contains a band near $1743 \mathrm{~cm}^{-1}$ that was attributed to the stretching vibrations of the carbonyl group of triglyceride esters $(-\mathrm{C}=\mathrm{O})[28,48,61]$. The intensity of this band was decreasing during the storage. In the same region, a strong band at $1644 \mathrm{~cm}^{-1}$ can be identified as $\mathrm{C}-\mathrm{H}$ bending vibrations of methylene, overlapping with the $\mathrm{O}-\mathrm{H}$ deformation of water present in the system. It may also contain the symmetrical stretching vibrations of conjugated $\mathrm{C}=\mathrm{C}$ at $1634 \mathrm{~cm}^{-1}$ [36]. This region covers peaks around 1658 and $1544 \mathrm{~cm}^{-1}$, which stand for the vibrations of amide I and II of protein [41,59].

The fingerprint region in 1500-900 $\mathrm{cm}^{-1}$ enclosed the $\mathrm{CH}_{2}$ bending band at $1452 \mathrm{~cm}^{-1}$, and the $\mathrm{C}-\mathrm{O} / \mathrm{CH}_{2}$ stretching and bending band at $1161 \mathrm{~cm}^{-1}$ [36,48,59]. The intensity of these bands increased during oxidation because of the decomposition of hydroperoxides through the $\beta$-scission mechanism $[11,36]$. The band at $1377 \mathrm{~cm}^{-1}$ was identified as $\mathrm{C}-\mathrm{H}$ bending vibrations of methyl groups. The area between 1250 and $800 \mathrm{~cm}^{-1}$ represents characteristic peaks of various $\mathrm{C}-\mathrm{O}$ vibrations in carbohydrates $[59,60]$. Another important band is the one at $968 \mathrm{~cm}^{-1}$, which corresponds to the $\mathrm{C}-\mathrm{H}$ out-of-plane deformation vibration of trans-double bonds. Its frequency increases during oxidation (cis-double bonds of unsaturated fatty acids undergo isomerization to the trans-form) $[28,48,62]$.

\subsubsection{Prediction of the Oxidation Levels of Infant Milk Formula (IMF) using ATR-FTIR}

Infant milk formulas were kept in the dark at 50,60 , and $70^{\circ} \mathrm{C}$. Through this work, 100 samples were analyzed from both preparations (no additives (No-AOx) and AOx with the ternary mixture of antioxidants). For some samples, the volatile formation was below the GC-MS detection threshold. These samples were disregarded, and a total of sixty-three samples was included in the PLSR method. Samples were divided randomly into a calibration set of 52 samples and a validation set of 11 samples. The volatile content ranged from 43,634 to 188,407 counts. However, a few of the samples showed high values for volatile compounds. This is likely due to the long study duration of 8 days at high temperature $\left(70^{\circ} \mathrm{C}\right)$. Samples also showed minor changes in viscosity and color, which may reflect other phenomena occurring in the same time. The statistic model correlates the sum of volatiles released during storage as measured by GC-MS and predicted from the ATR-FTIR spectral changes in the range of 4000 to $600 \mathrm{~cm}^{-1}$. The coefficients of determination (Corr. Coeff), root mean square errors of calibration (RMSEC) and prediction (RMSEP), and the number of factors used and other parameters are summarized in Table 1.

Table 1. Summary of ATR-FTIR and near-infrared (NIR) prediction models used to detect volatiles content in infant milk formula: models' parameters, number of samples, and results.

\begin{tabular}{ccc}
\hline Prediction Model & ATR-FTIR & NIRS \\
\hline Spectral range & $4000-600 \mathrm{~cm}^{-1}$ & $800-2400 \mathrm{~nm}$ \\
\hline Pretreatment & $\begin{array}{c}\text { Standard normal variate } \\
(\text { SNV)-baseline correction }\end{array}$ & $\begin{array}{c}\text { Second derivative (gap 23 points, } \\
\text { segment 19 points) }\end{array}$ \\
\hline Calibration set (samples) & 52 & 50 \\
\hline Validation set (samples) & 11 & 10 \\
\hline Volatiles content range (counts) & $43,634-188,407$ & 3 \\
\hline Number of latent variables & 7 & 0.921 \\
\hline Coefficient of correlation for calibration $\left(\mathrm{R}^{2}\right)$ & $0.877-142,015$ \\
\hline Coefficient of correlation for prediction $\left(\mathrm{R}^{2}\right)$ & 0.904 & 0.919 \\
\hline Error of calibration (RMSEC) & 14,500 counts $(18 \%)$ & 8180 counts $(11.4 \%)$ \\
\hline Error of prediction (RMSEP) & 14,000 counts $(17.5 \%)$ & 6400 counts $(9 \%)$ \\
\hline RMSEC/RMSEP $(<1.2)$ & 0.96 & 0.78 \\
\hline Volatiles content/RMSEP & 10.34 & 15.37
\end{tabular}

RMSEC, root mean square errors of calibration; RMSEP, root mean errors of prediction. 
Seven factors were selected for this model (respecting the lower error of calibration) (Figure 5). The correlation coefficients were 0.8775 and 0.904 for calibration and prediction, respectively. The errors of calibration (RMSEC) and prediction (RMSEP) were $18 \%$ and $17.5 \%$.

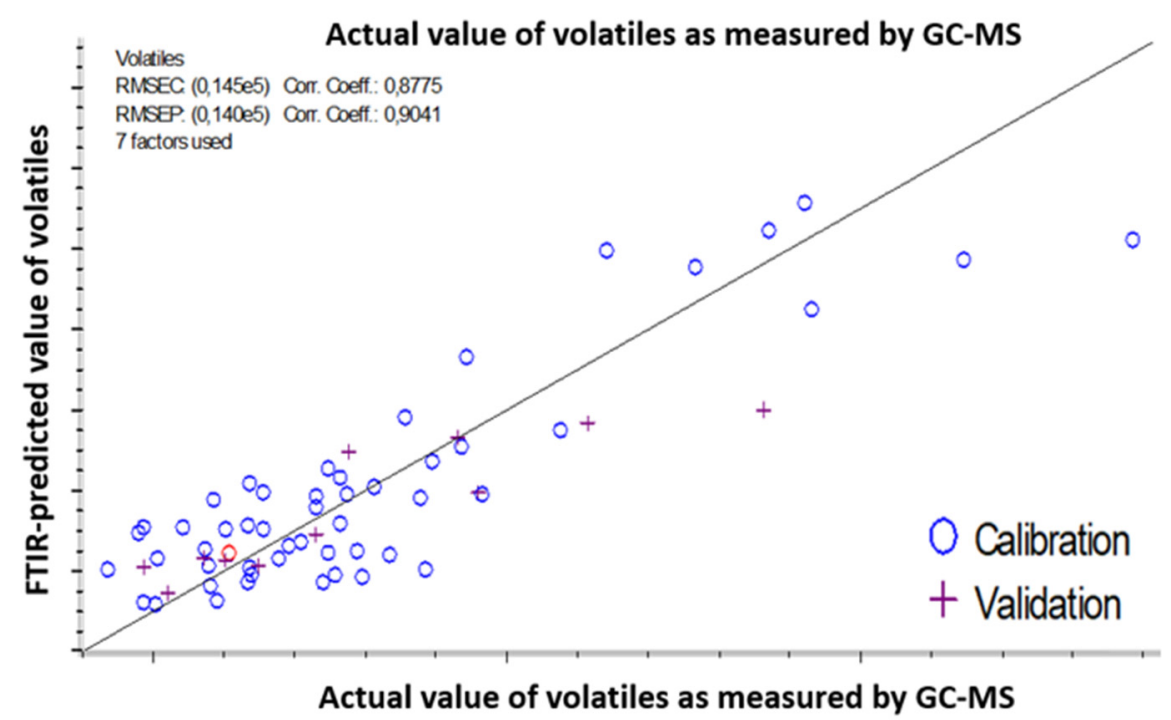

Figure 5. Partial least squares regression (PLSR) analysis prediction model of the oxidation level of liquid milk infant formula: correlation between the actual value of volatiles as measured by headspace solid-phase microextraction gas chromatography coupled to mass spectrometry (HS-SPME-GC-MS) $(x$-axis) and the volatiles values predicted from the spectral changes happening over the whole spectral range of ATR-FTIR spectra (y_axis).

Samples were a mixture of infant milk formula with and without the added antioxidant mixture (lecithin, citric acid, and ascorbyl palmitate) at different days (1 to 8$)$ and temperature $\left(50,60\right.$, and $70{ }^{\circ} \mathrm{C}$ ) of storage.

The ATR-FTIR model is suitable for quality control: the ratio of volatile content range to the error of prediction is superior to 10 . These findings proved that the quality of the prediction model is strictly related to the ability of standard methods to accurately monitor lipid oxidation.

\subsection{Infrared Spectroscopy in the Near-Region (NIRS) Applied on Infant Milk Formulas}

\subsubsection{Spectral Changes of Infant Milk Formulas}

The NIR spectra of IMF were recorded in the range of 1000 to $2500 \mathrm{~nm}$. Derivation allowed the revealing of other bands in addition to the two broad bands of water at 1450 and $1940 \mathrm{~nm}$ (Figure 6). The spectra were divided into five ranges. The main peaks and their attribution are summarized in Table 2.

The first part of the NIR spectrum (1120 to $1280 \mathrm{~nm}$ ) represents the second overtone of C-H from $\mathrm{CH}_{3}, \mathrm{CH}_{2}$, and $\mathrm{CH}$. The second region (1300-1600 nm) combines the first overtone of combinations $\mathrm{C}-\mathrm{H}$ for $\mathrm{CH}_{3}, \mathrm{CH}_{2}$, and $\mathrm{CH}$, and the first overtone of $\mathrm{O}-\mathrm{H}\left(\mathrm{H}_{2} \mathrm{O}\right.$ water) and $\mathrm{N}-\mathrm{H}$ (CONHR proteins). The third region (1630-1820 $\mathrm{nm}$ ) represents the first overtone of $\mathrm{C}-\mathrm{H}$ for $\mathrm{CH}_{3}, \mathrm{CH}_{2}$, and $\mathrm{CH}$. The part of spectra from 1820 to $2180 \mathrm{~nm}$ combines the second overtone of $\mathrm{C}=\mathrm{O}$ and combinations bands of $\mathrm{O}-\mathrm{H}$. The last part $(2180-2500 \mathrm{~nm})$ represents the combinations of $\mathrm{NH}-\mathrm{OH}$ and combinations from $\mathrm{CH}-\mathrm{CC}$ and CC-CC.

Samples without antioxidants were stored in the dark at $70{ }^{\circ} \mathrm{C}$. Samples were analyzed during 8 days. More variations were detected after the application of a second gap ( 23 points) segment (19 points) derivation. 


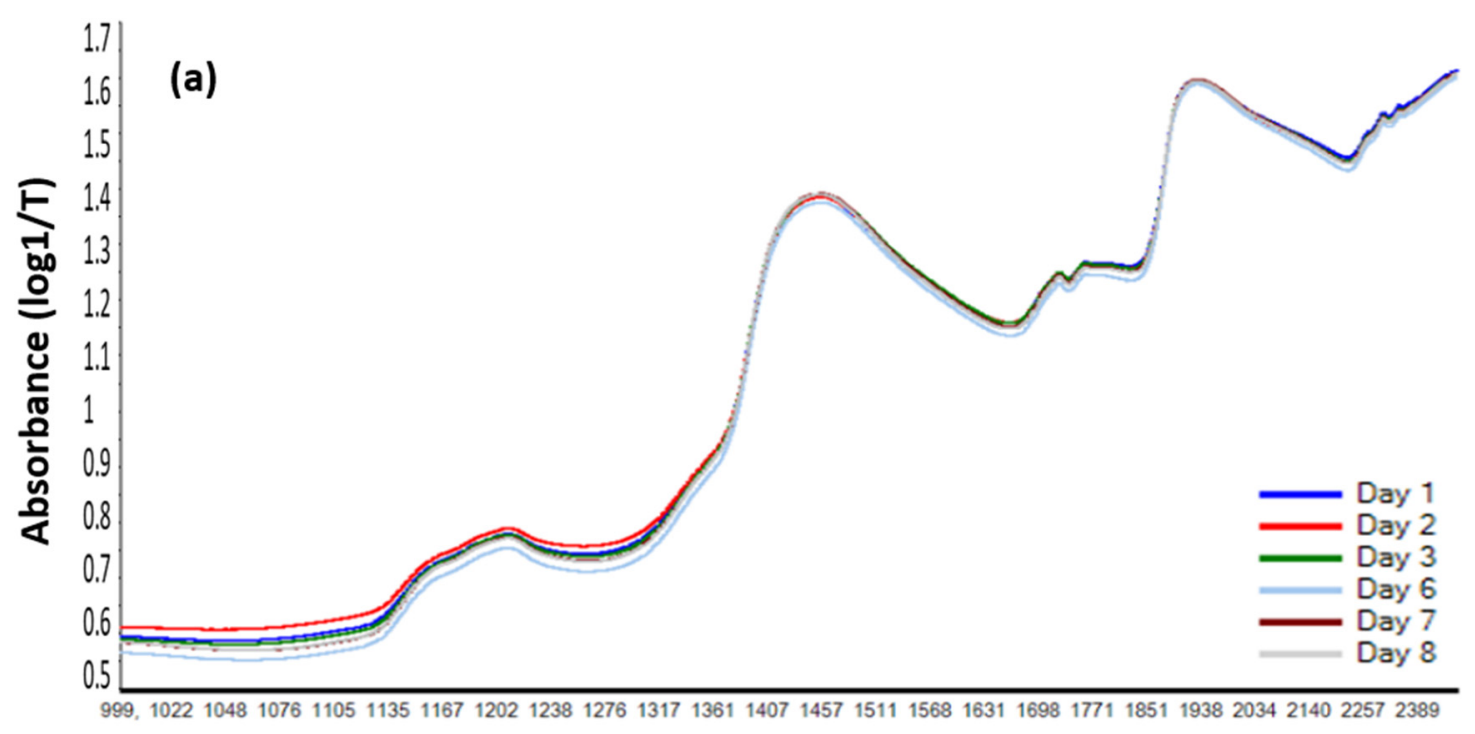

Wavelength $(\mathrm{nm})$

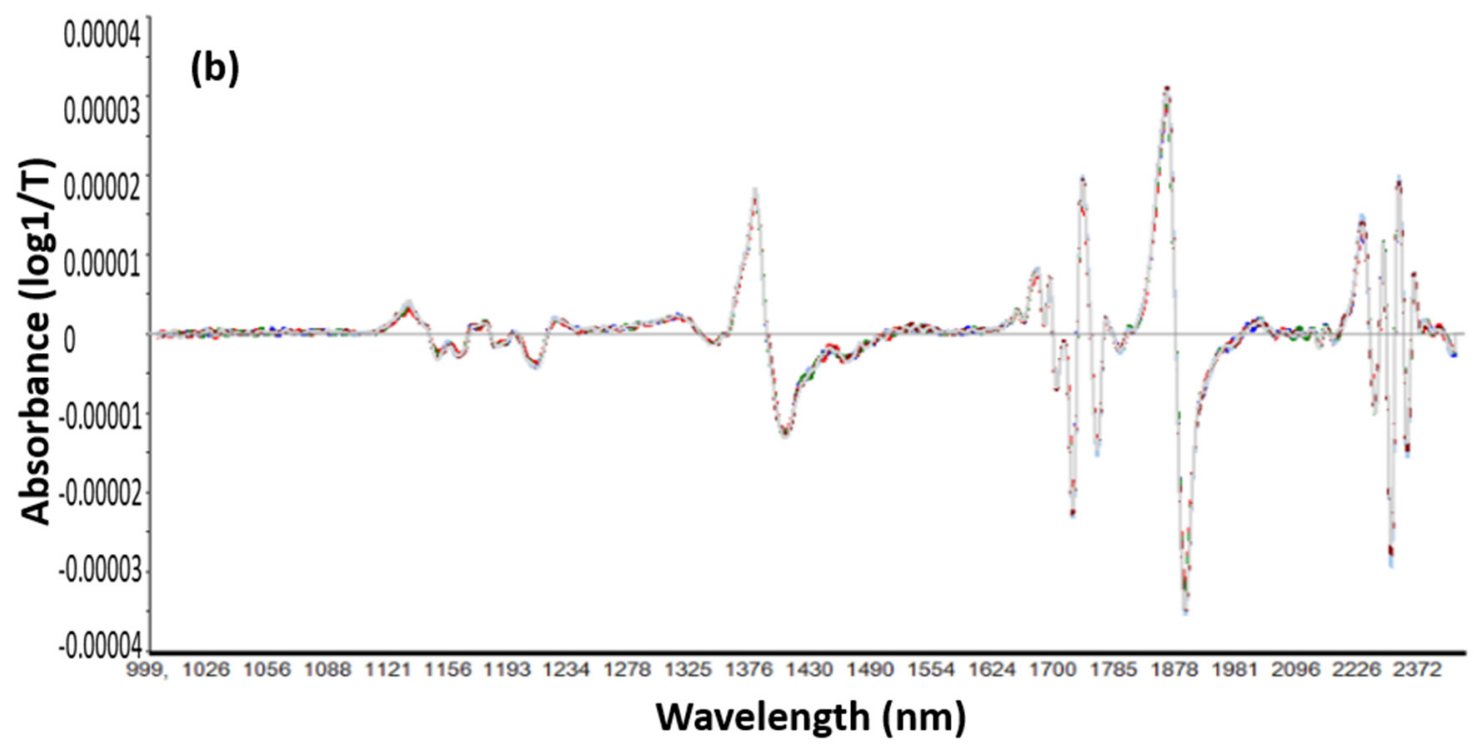

Figure 6. Variation of near infrared spectra of liquid infant milk formula; (a) raw, (b) first derivative of the NIR signal.

Table 2. Major bands in NIR spectra of infant milk formula $[21,41,45,60]$.

\begin{tabular}{cccc}
\hline Range & Wavelength $(\mathbf{n m})$ & Functional Group & Attribution \\
\hline 1 & $1120-1280$ & $1160 / 1210$ sStretching $\mathrm{C}-\mathrm{H}$ second overtone of & Fat \\
& & $\mathrm{CH}_{3}$ and $\mathrm{CH}_{2}$ & $1440 \mathrm{O}-\mathrm{H}$ \\
Water \\
2 & $1280-1600$ & 1483 and $1570 \mathrm{~N}-\mathrm{H}$ first overtone & Protein \\
& & $\mathrm{C}-\mathrm{H}$ first overtone & Fat \\
3 & $1630-1820$ & 1726 and $1765 \mathrm{C}-\mathrm{H}$ first overtone for $\mathrm{CH}_{2} \mathrm{CH}$ & Fat \\
4 & $1820-2180$ & $1950-$ deformation and stretching of $\mathrm{O}-\mathrm{H}$ & Water \\
& & $1992 / 2110 \mathrm{~N}-\mathrm{H}$ stretching & Protein \\
& $2180-2500$ & $2280 \mathrm{~N}-\mathrm{H} / 2308 \mathrm{C}-\mathrm{H}$ & Protein \\
5 & & $2310 / 2354 \mathrm{C}-\mathrm{H}$ & Fat \\
& & 2347 stretching $\mathrm{CH}_{2}$ and deformation of $=\mathrm{CH}_{2}$ & Carbohydrate \\
& & 2264 and 2494 &
\end{tabular}




\subsubsection{Prediction of the Oxidation Level of IMF using NIRS}

Infant milk formulas were kept in the dark at 50,60 , and $70^{\circ} \mathrm{C}$. Similarly, all samples with total volatiles content below the GC-MS detection limit were excluded and sixty samples were kept for the PLSR model. Samples were once again, divided randomly into calibration and validation sets with 50 and 10 samples, respectively. The sum of volatiles ranged from 43,634 to 142,015 counts, with a mean value of 71,410 counts. The entire spectral range was used to create the prediction model. The parameters used to prepare the NIR prediction model are presented in Table 1.

Three factors were selected for this model. The low number of factors increases the robustness of the model. The scatter plot of predicted (from NIRS) and measured values of the sum of volatiles is presented in Figure 7.

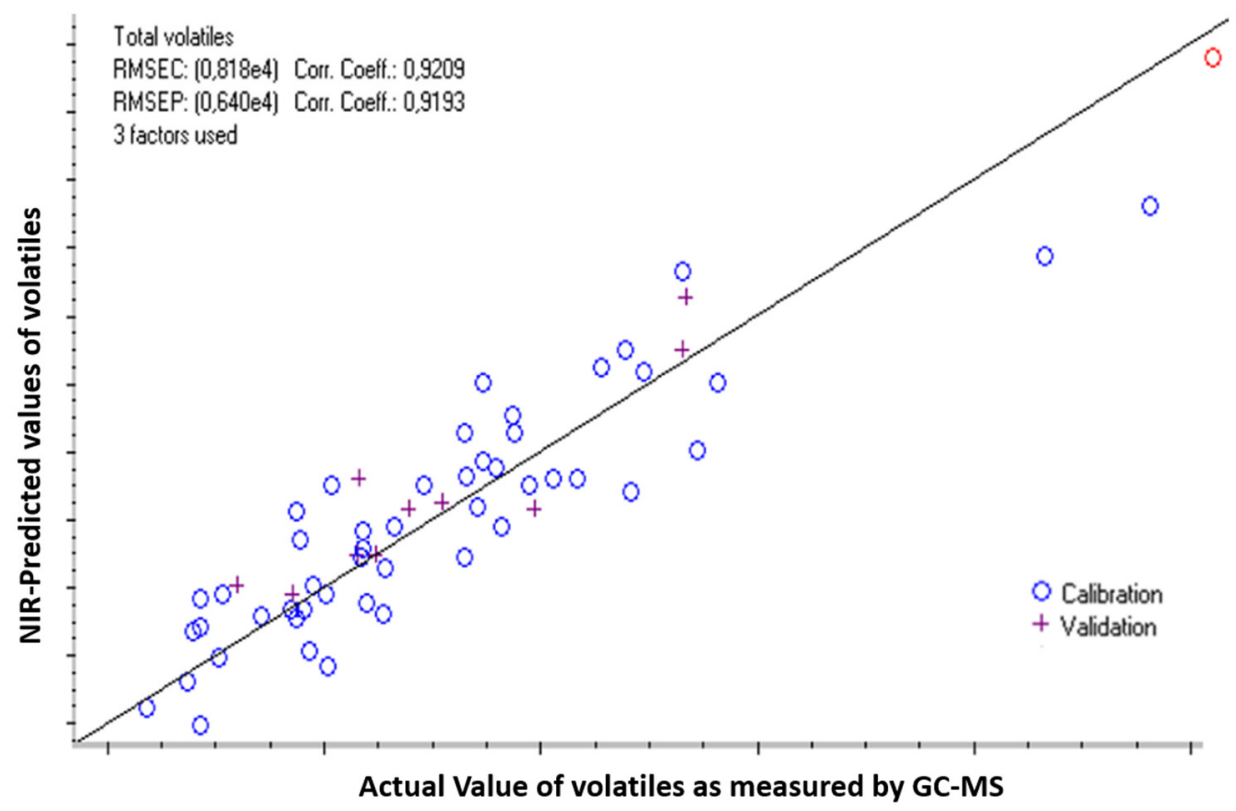

Figure 7. PLSR prediction model for lipid oxidation of infant milk formula using near-infrared spectroscopy (NIR).

The scatter plot presents in the $x$-axis the value of the sum of volatiles formed during the storage of liquid infant milk formula (fat oxidation measured by SPME-GC-MS) to the calculated values from the spectral changes during storage (NIR-predicted volatiles value) (y-axis). Samples used to build this model were a pool of infant milk formulas with and without the added antioxidant mixture, at different days and temperature of storage.

The characteristics of the NIRS-prediction model are detailed in Table 1. The coefficients of determination $\left(\mathrm{R}^{2}\right)$ of calibration and prediction were 0.921 and 0.919 , respectively. The errors of calibration and prediction were 8180 counts $(11.4 \%)$ and 6400 counts $(9 \%)$, respectively. The ratio of the error of prediction (RMSEP) to the error of calibration (RMSEC) was $0.78(<1.2)$. Since the ratio of data range to the error of prediction was $15.3(>15)$. Consequently, this model could be used for quantification purposes [50].

The prediction models developed in this study, were designed to detect the lipid oxidation in infant milk. To the authors' knowledge, this is the first time, that infrared spectroscopy is used for oxidation monitoring in liquid infant milk formulas. However, multiple regression models can be applied to one recorded infrared spectrum. Therefore, this prediction model can be combined to other product characteristics such as composition, oxidation, and physical proprieties can be simultaneously monitored. 


\section{Conclusions}

Infrared spectroscopy could detect lipid oxidation in infant formula containing relatively high levels of unsaturated fats. The ATR-FTIR prediction model may present a useful tool for quality control in emulsion applications. The NIR prediction model may even serve to quantify oxidation in these complex matrices. Infrared spectroscopy has the potential to replace standard techniques, avoiding time-consuming and costly sample preparation. Once the prediction model is calibrated and validated for a given sample and setup, a simple acquisition of infrared spectra is needed to evaluate the oxidation level of samples. Furthermore, novel portable infrared spectrophotometers or devices with narrow optical fibers are now available on the market. ATR-FTIR and NIRS may therefore be implemented in dairy industries for quality control or research and development purposes. Such implementation helps reduce time, effort, and cost. Multiple regression models can be applied to the spectral information, which in addition to the lipid oxidation level, may offer additional insights into other parameters (water, protein, and sugar contents) of the final product. For application developers, these tools offer the ability to rapidly test different mixtures and formulations. To improve the quality and performance of the prediction models, the acceleration conditions should be wisely chosen to ensure measurable oxidation levels but also conserve the physical stability of samples. The viscosity of the studied preparations could influence the lipid oxidation kinetics and volatiles releases. The efficiency of the prediction model is directly related to the accuracy and repeatability of the reference methods. In our case, the conjugated dienes method was unable to quantify low oxidation levels. Analysis of volatiles by SPME-GC-MS may be considered as a very sensitive and efficient method. However, here too optimization is needed, with an appropriate choice of standards and matrix to test. Accordingly, the infrared spectroscopic methods developed herein offer the possibility to predict oxidative processes and to establish optimization strategies for the development of infant formulas.

Supplementary Materials: The following are available online at http://www.mdpi.com/2304-8158/9/10/1432/s1, Figure S1: The content of Hexanal (area responses in counts) released from infant milk formula under different storage conditions, Figure S2: The content of 2,4-decadienal (area responses in counts) released from infant milk formula under different storage conditions, Figure S3: Variation of ATR-FTIR spectra of liquid infant milk formula with antioxidant.

Author Contributions: Conceptualization, B.H., E.B.-M. and P.C.; methodology, S.D., B.H. and P.C.; software, S.D.; validation, S.D.; formal analysis, S.D. and B.H.; investigation, S.D. and E.B.-M.; resources, S.D.; data curation, S.D.; writing—original draft preparation, S.D.; writing—review and editing, S.D., B.H., E.B.-M., G.W., R.M., N.B. and P.C.; visualization, S.D.; supervision, E.B.-M., G.W., R.M. and N.B.; project administration, P.C.; funding acquisition, G.W. and P.C. All authors have read and agreed to the published version of the manuscript.

Funding: The authors gratefully acknowledge our partner Cargill, the "Fonds Européen de Developpement Régional" (FEDER), and the Regional Council of Bourgogne-Franche-Comté, for their financial support.

Conflicts of Interest: The authors declare that there is no conflict of interest.

\section{References}

1. Endo, J.; Arita, M. Cardioprotective mechanism of omega-3 polyunsaturated fatty acids. J. Cardiol. 2016, 67, 22-27. [CrossRef] [PubMed]

2. Kerdiles, O.; Layé, S.; Calon, F. Omega-3 polyunsaturated fatty acids and brain health: Preclinical evidence for the prevention of neurodegenerative diseases. Trends Food Sci. Technol. 2017, 69, 203-213. [CrossRef]

3. EFSA Scientific Opinion on the substantiation of a health claim related to DHA and contribution to normal brain development pursuant to Article 14 of Regulation (EC) No 1924/2006. EFSA J. 2014, 12, 3840. [CrossRef]

4. Taneja, A.; Singh, H. Challenges for the delivery of long-chain n-3 fatty acids in functional foods. Annu. Rev. Food Sci. Technol. 2012, 3, 105-123. [CrossRef]

5. European Union. Public Office of the European Commission Delegated Regulation (EU) 2016/127 of 25 September 2015 supplementing Regulation (EU) No 609/2013 of the European Parliament and of the Council as regards the specific compositional and information requirements for infant formula and follow-on formula and as regards requirements on information relating to infant and young child feeding (Text with EEA relevance). Off. J. Eur. Union 2015. 
6. Innis, S.M. Human milk: Maternal dietary lipids and infant development. Proc. Nutr. Soc. 2007, 66, 397-404. [CrossRef]

7. Venkataraman, S.; Schafer, F.Q.; Buettner, G.R. Detection of lipid radicals using EPR. Antioxid. Redox Signal. 2004, 6, 631-638. [CrossRef]

8. Clarke, H.J.; O'Sullivan, M.G.; Kerry, J.P.; Kilcawley, K.N. Correlating volatile lipid oxidation compounds with consumer sensory data in dairy based powders during storage. Antioxidants 2020, 9, 338. [CrossRef]

9. Cesa, S.; Casadei, M.A.; Cerreto, F.; Paolicelli, P. Infant milk formulas: Effect of storage conditions on the stability of powdered products towards autoxidation. Foods 2015, 4, 487-500. [CrossRef]

10. Siefarth, C.; Serfert, Y.; Drusch, S.; Buettner, A. Comparative evaluation of diagnostic tools for oxidative deterioration of polyunsaturated fatty acid-enriched infant formulas during storage. Foods 2014, 3, 30-65. [CrossRef]

11. Frankel, E.N. Lipid Oxidation, 2nd ed.; Woodhead Publishing: Oakland, CA, USA, 2015; ISBN 978-0-85709-792-7.

12. Liao, H.; Zhu, M.; Chen, Y. 4-Hydroxy-2-nonenal in food products: A review of the toxicity, occurrence, mitigation strategies and analysis methods. Trends Food Sci. Technol. 2020, 96, 188-198. [CrossRef]

13. Sottero, B.; Leonarduzzi, G.; Testa, G.; Gargiulo, S.; Poli, G.; Biasi, F. Lipid Oxidation Derived Aldehydes and Oxysterols Between Health and Disease. Eur. J. Lipid Sci. Technol. 2019, 121, 1700047. [CrossRef]

14. Let, M.B.; Jacobsen, C.; Frankel, E.N.; Meyer, A.S. Oxidative flavour deterioration of fish oil enriched milk. Eur. J. Lipid Sci. Technol. 2003, 105, 518-528. [CrossRef]

15. Velasco, J.; Marmesat Rodas, S.; Holgado, F.; Márquez-Ruiz, G.; Dobarganes, M. Influence of two lipid extraction procedures on the peroxide value in powdered infant formulas. Eur. Food Res. Technol. 2008, 226, 1159-1166. [CrossRef]

16. Cesa, S.; Casadei, M.A.; Cerreto, F.; Paolicelli, P. Influence of fat extraction methods on the peroxide value in infant formulas. Food Res. Int. 2012, 48, 584-591. [CrossRef]

17. Asaduzzaman, M.; Biasioli, F.; Cosio, M.S.; Schampicchio, M. Hexanal as biomarker for milk oxidative stress induced by copper ions. J. Dairy Sci. 2017, 100, 1650-1656. [CrossRef]

18. Cheng, H.; Zhu, R.-G.; Erichsen, H.; Soerensen, J.; Petersen, M.A.; Skibsted, L.H. High temperature storage of infant formula milk powder for prediction of storage stability at ambient conditions. Int. Dairy J. 2017, 73, 166-174. [CrossRef]

19. Cen, H.; He, Y. Theory and application of near infrared reflectance spectroscopy in determination of food quality. Trends Food Sci. Technol. 2007, 18, 72-83. [CrossRef]

20. Xu, J.-L.; Riccioli, C.; Sun, D.-W. An overview on nondestructive spectroscopic techniques for lipid and lipid oxidation analysis in fish and fish products. Compr. Rev. Food Sci. Food Saf. 2015, 14, 466-477. [CrossRef]

21. Christy, A.A.; Kasemsumran, S.; Du, Y.; Ozaki, Y. The detection and quantification of adulteration in olive oil by near-infrared spectroscopy and chemometrics. Anal. Sci. Int. J. Jpn. Soc. Anal. Chem. 2004, 20, 935-940. [CrossRef]

22. Vlachos, N.; Skopelitis, Y.; Psaroudaki, M.; Konstantinidou, V.; Chatzilazarou, A.; Tegou, E. Applications of Fourier transform-infrared spectroscopy to edible oils. Anal. Chim. Acta 2006, 573-574, 459-465. [CrossRef] [PubMed]

23. Büning-Pfaue, H. Analysis of water in food by near infrared spectroscopy. Food Chem. 2003, 82, 107-115. [CrossRef]

24. Kays, S.E.; Barton, F.E.; Windham, W.R. Predicting Protein Content by near infrared reflectance spectroscopy in diverse cereal food products. J. Infrared Spectrosc. 2000, 8, 35-43. [CrossRef]

25. Moh, M.H.; Che Man, Y.B.; van de Voort, F.R.; Abdullah, W.J.W. Determination of peroxide value in thermally oxidized crude palm oil by near infrared spectroscopy. J. Am. Oil Chem. Soc. 1999, 76, 19-23. [CrossRef]

26. Wójcicki, K.; Khmelinskii, I.; Sikorski, M.; Sikorska, E. Near and mid infrared spectroscopy and multivariate data analysis in studies of oxidation of edible oils. Food Chem. 2015, 187, 416-423. [CrossRef] [PubMed]

27. Yildiz, G.; Wehling, R.L.; Cuppett, S.L. Method for determining oxidation of vegetable oils by near-infrared spectroscopy. J. Am. Oil Chem. Soc. 2001, 78, 495-502. [CrossRef]

28. Borchman, D.; Sinha, S. Determination of products of lipid oxidation by infrared spectroscopy. In Oxidative Stress Biomarkers and Antioxidant Protocols; Armstrong, D., Ed.; Methods in Molecular Biology ${ }^{\mathrm{TM}}$; Humana Press: Totowa, NJ, USA, 2002; pp. 21-28, ISBN 978-1-59259-173-2. 
29. Klaypradit, W.; Kerdpiboon, S.; Singh, R. Application of artificial neural networks to predict the oxidation of menhaden fish oil obtained from fourier transform infrared spectroscopy method. Food Bioprocess. Technol. 2011, 4, 475-480. [CrossRef]

30. Lerma-García, M.J.; Simó-Alfonso, E.F.; Bendini, A.; Cerretani, L. Rapid evaluation of oxidised fatty acid concentration in virgin olive oil using Fourier-transform infrared spectroscopy and multiple linear regression. Food Chem. 2011, 124, 679-684. [CrossRef]

31. Setiowaty, G.; Che Man, Y.B. A rapid Fourier transform infrared spectroscopic method for the determination of 2-TBARS in palm olein. Food Chem. 2003, 81, 147-154. [CrossRef]

32. Daoud, S.; Bou-maroun, E.; Dujourdy, L.; Waschatko, G.; Billecke, N.; Cayot, P. Fast and direct analysis of oxidation levels of oil-in-water emulsions using ATR-FTIR. Food Chem. 2019, 293, 307-314. [CrossRef]

33. Daoud, S.; Waschatko, G.; Bou-Maroun, E.; Cayot, P. Fast, direct and in situ monitoring of lipid oxidation in an oil-in-water emulsion by near infrared spectroscopy. Anal. Methods 2020, 12, 3098-3105. [CrossRef] [PubMed]

34. BELHAJ, N.; Arab-Tehrany, E.; Linder, M. Oxidative kinetics of salmon oil in bulk and in nanoemulsion stabilized by marine lecithin. Process. Biochem. 2010, 45, 187-195. [CrossRef]

35. Guzun-Cojocaru, T.; Koev, C.; Yordanov, M.; Karbowiak, T.; Cases, E.; Cayot, P. Oxidative stability of oil-in-water emulsions containing iron chelates: Transfer of iron from chelates to milk proteins at interface. Food Chem. 2011, 125, 326-333. [CrossRef]

36. Hayati, I.N.; Man, Y.B.C.; Tan, C.P.; Aini, I.N. Monitoring peroxide value in oxidized emulsions by Fourier transform infrared spectroscopy. Eur. J. Lipid Sci. Technol. 2005, 107, 886-895. [CrossRef]

37. Nalur, S.; Decker, E.A. Rapid, sensitive, iron-based spectrophotometric methods for determination of peroxide values of food lipids. J. AOAC Int. 1994, 77, 421-424.

38. Jensen, P.N.; Sørensen, G.; Engelsen, S.B.; Bertelsen, G. Evaluation of quality changes in walnut kernels (Juglans regia L.) by Vis/NIR spectroscopy. J. Agric. Food Chem. 2001, 49, 5790-5796. [CrossRef]

39. Kaddour, A.A.; Grand, E.; Barouh, N.; Baréa, B.; Villeneuve, P.; Cuq, B. Near-infrared spectroscopy for the determination of lipid oxidation in cereal food products. Eur. J. Lipid Sci. Technol. 2006, 108, 1037-1046. [CrossRef]

40. Ni, Y.; Mei, M.; Kokot, S. Analysis of complex, processed substances with the use of NIR spectroscopy and chemometrics: Classification and prediction of properties-The potato crisps example. Chemom. Intell. Lab. Syst. 2011, 105, 147-156. [CrossRef]

41. Wang, X.; Esquerre, C.; Downey, G.; Henihan, L.; O'Callaghan, D.; O’Donnell, C. Assessment of infant formula quality and composition using Vis-NIR, MIR and Raman process analytical technologies. Talanta 2018, 183, 320-328. [CrossRef]

42. Gredilla, A.; Fdez-Ortiz de Vallejuelo, S.; Elejoste, N.; de Diego, A.; Madariaga, J.M. Non-destructive Spectroscopy combined with chemometrics as a tool for Green Chemical Analysis of environmental samples: A review. TrAC Trends Anal. Chem. 2016, 76, 30-39. [CrossRef]

43. He, Y.; Tang, L.; Wu, X.; Hou, X.; Lee, Y.-I. Spectroscopy: The best way toward green analytical chemistry? Appl. Spectrosc. Rev. 2007, 42, 119-138. [CrossRef]

44. AOCS Spectrophotometric Determination of Conjugated Dienoic Acid- Ti 1a-64. Off. Methods Recomm. Pr. Am. Oil Chem. Soc. 2009. Available online: https://www.aocs.org/attain-lab-services/methods/methods/ search-results?method=111546 (accessed on 1 October 2020).

45. Tsenkova, R.; Atanassova, S.; Itoh, K.; Ozaki, Y.; Toyoda, K. Near infrared spectroscopy for biomonitoring: Cow milk composition measurement in a spectral region from 1100 to 2400 nanometers. J. Anim. Sci. 2000, 78, 515. [CrossRef]

46. Esbensen, K.H. Multivariate Data Analysis-In Practice: An Introduction to Multivariate Data Analysis and Experimental Design, 5th ed.; CAMO: Oslo, Norway, 2012; ISBN 978-82-993330-3-0.

47. Brereton, R.G. Chemometrics: Data Analysis for the Laboratory and Chemical Plant; Wiley: Chichester, UK, 2006; ISBN 978-0-471-48977-1.

48. Cebi, N.; Yilmaz, M.T.; Sagdic, O.; Yuce, H.; Yelboga, E. Prediction of peroxide value in omega-3 rich microalgae oil by ATR-FTIR spectroscopy combined with chemometrics. Food Chem. 2017, 225, 188-196. [CrossRef] [PubMed]

49. Westad, F.; Marini, F. Validation of chemometric models-A tutorial. Anal. Chim. Acta 2015, 893, 14-24. [CrossRef] [PubMed] 
50. AACC Near-Infrared Methods-Guidelines for Model Development and Maintenance. AACC Int. Approv. Methods 2009. Available online: http://methods.aaccnet.org/summaries/39-00-01.aspx (accessed on 1 October 2020).

51. Mendonça, M.A.; Araújo, W.M.C.; Borgo, L.A.; De Rodrigues Alencar, E. Lipid profile of different infant formulas for infants. PLoS ONE 2017, 12, e0177812. [CrossRef] [PubMed]

52. Frankel, E.N. Volatile lipid oxidation products. Prog. Lipid Res. 1983, 22, 1-33. [CrossRef]

53. Shi, H.; Ho, C.-T. The flavour of poultry meat. In Flavor of Meat and Meat Products; Shahidi, F., Ed.; Springer US: Boston, MA, USA, 1994; pp. 52-70, ISBN 978-1-4613-5911-1.

54. Choe, J.; Oh, B.; Choe, E. Effect of soybean lecithin on iron-catalyzed or chlorophyll-photosensitized oxidation of canola oil emulsion. J. Food Sci. 2014, 79, C2203-C2208. [CrossRef]

55. Doert, M.; Jaworska, K.; Moersel, J.-T.; Kroh, L.W. Synergistic effect of lecithins for tocopherols: Lecithin-based regeneration of $\alpha$-tocopherol. Eur. Food Res. Technol. 2012, 235, 915-928. [CrossRef]

56. Samdani, G.K.; McClements, D.J.; Decker, E.A. Impact of phospholipids and tocopherols on the oxidative stability of soybean oil-in-water emulsions. J. Agric. Food Chem. 2018, 66, 3939-3948. [CrossRef] [PubMed]

57. Cho, Y.-J.; Alamed, J.; McClements, D.J.; Decker, E.A. Ability of chelators to alter the physical location and prooxidant activity of iron in oil-in-water emulsions. J. Food Sci. 2003, 68, 1952-1957. [CrossRef]

58. Kristinova, V.; Aaneby, J.; Mozuraityte, R.; Storrø, I.; Rustad, T. The effect of dietary antioxidants on iron-mediated lipid peroxidation in marine emulsions studied by measurement of dissolved oxygen consumption. Eur. J. Lipid Sci. Technol. 2014, 116, 857-871. [CrossRef]

59. Lei, Y.; Zhou, Q.; Zhang, Y.; Chen, J.; Sun, S.; Noda, I. Analysis of crystallized lactose in milk powder by Fourier-transform infrared spectroscopy combined with two-dimensional correlation infrared spectroscopy. J. Mol. Struct. 2010, 974, 88-93. [CrossRef]

60. Sivakesava, S.; Irudayaraj, J. Rapid determination of tetracycline in milk by FT-MIR and FT-NIR spectroscopy. J. Dairy Sci. 2002, 85, 487-493. [CrossRef]

61. Guillen, M.; Cabo, N. Some of the most significant changes in the Fourier transform infrared spectra of edible oils under oxidative conditions. J. Sci. Food Agric. 2000, 80, 2028-2036. [CrossRef]

62. Kim, Y.; Himmelsbach, D.S.; Kays, S.E. ATR-Fourier transform mid-infrared spectroscopy for determination of trans fatty acids in ground cereal products without oil extraction. J. Agric. Food Chem. 2007, 55, 4327-4333. [CrossRef]

(C) 2020 by the authors. Licensee MDPI, Basel, Switzerland. This article is an open access article distributed under the terms and conditions of the Creative Commons Attribution (CC BY) license (http://creativecommons.org/licenses/by/4.0/). 